\title{
PLANEAMIENTO REGIONAL INDUSTRIAL Y CULTURAL EUROPEO Comparativa de políticas territoriales en la región del Ruhr y Barcelona
}

\author{
Kyra Romero Branchadell \\ Escuela Técnica Superior de Arquitectura de Barcelona (ETSAB) \\ Universidad Politécnica de Barcelona (UPC) \\ Directores de tesis: Joaquín Sabaté y Melisa Pessoa \\ kyra.rb@outlook.com
}

\section{RESUMEN}

Las regiones industriales europeas propiciaron en su origen el desarrollo de mecanismos de gestión territorial y continúan innovando en este ámbito con una nueva perspectiva de regeneración cultural. Estas estrategias tienen un interés singular por impulsar el desarrollo de amplios territorios con un claro objetivo descentralizador y poliédrico. Para analizar la evolución de estas tendencias en Europa se comparan dos casos de estudio paradigmáticos: la región del Ruhr y la provincia de Barcelona. Este artículo no pone su foco en grandes ciudades, sino en las sinergias entre ciudades intermedias y los mecanismos de relación entre ellas formando dos regiones europeas de alto interés desde el punto de vista industrial, cultural y natural. Por tanto, el objetivo es poner en valor las redes culturales que crean un nuevo nivel de conexión, para junto a las redes naturales y de infraestructuras, consolidar tejidos urbanos y territoriales atractivos, dinámicos y cohesionados.

Palabras Clave: Patrimonio Industrial, Redes Culturales, Planeamiento territorial, Descentralización.

\section{ABSTRACT}

European industrial regions fostered the development of new territorial planning tools and they keep innovating in this field with cultural regeneration policies. These strategies have a special interest because they promote the development of vast territories with a clear decentralizing and polycentric objectives. In order to analyse the evolution of this trends in Europe, we compare two paradigmatic study cases: the Ruhr region and the province of Barcelona. This article focuses not in big cities, but in medium ones and the synergies that they build between each other. The mechanisms that regulate these connections in both cases are highly important from different perspectives: industrial, cultural and natural. Therefore, the objective of this study is to emphasise the value of cultural networks that add a new level of complexity. Together with the natural and the infrastructure networks, they create attractive, dynamic and cohesive urban and territorial tissues.

Key words: Industrial Heritage, Cultural Networks, Territorial Planning, Decentralization. 


\section{CONCEPTOS CLAVE, PLANIFICACIÓN INDUSTRIAL Y CULTURAL DESCENTRALIZADA}

Diferentes autores tienen en cuenta la relación entre el desarrollo cultural y urbano de las últimas décadas en Europa Occidental. En Políticas Culturales y Regeneración Urbana (Bianchini y Parkinson, 1993), se analiza el papel creciente de la cultura en la transformación urbana de urbes europeas como Liverpool, Rotterdam o Bilbao. La mayoría de ellas ven en el sector cultural una oportunidad para el territorio y las personas como sustitución de un sector industrial en declive. Este proceso requiere de la consideración de factores no sólo urbanos sino también sociales y políticos. "En concreto, el renacimiento cultural de las ciudades no capitales de Europa, [...] fueron promovidas por políticas nacionales para la descentralización desde el poder central hacia los gobiernos locales y regionales, la emergencia de movimientos sociales demandando nuevos tipos de cultura, y [...] como una herramienta valiosa para diversificar la economía local y conseguir una mayor cohesión social" (Bianchini y Parkinson, 1993).

Desde la publicación de ese libro, nuevas crisis económicas y sociales han asolado Europa y gran parte del mundo. Además la globalización ha recrudecido la competición constante entre ciudades por atraer inversión y capital humano cualificado. Por tanto, para que ciudades intermedias destaquen, o lo que es lo mismo, para sobrevivir en el panorama internacional de concentración de población en grandes urbes, hacen falta buenas políticas territoriales. Este artículo compara dos casos ejemplares de planificación estratégica descentralizada: la provincia de Barcelona en Cataluña y la región del Ruhr en el estado federal de Renania del Norte-Westfalia. En concreto se estudian cuatro ciudades por su pertenencia a diferentes redes culturales, para ver la evolución de la planificación del territorio al que pertenecen a lo largo del tiempo. Las ciudades escogidas en la provincia de Barcelona son Terrassa, Igualada, Manlleu y el barrio de Poblenou (Barcelona); en el contexto alemán se escogen Duisburg, Essen, Bochum y Dortmund. Las políticas territoriales de estos territorios surgen primero en el contexto industrial para salvaguardar zonas verdes y proveer de buenas redes de transporte, y se están fortaleciendo en un contexto digital con redes culturales.

¿Qué elementos catalizan la recuperación y reactivación monumental y cultural en las ciudades industriales europeas contemporáneas? Sin duda, la situación de abandono de las antiguas fábricas obsoletas se ha transformado en oportunidad, en un intento por generar gran impacto con poco presupuesto, en la mayoría de zonas no céntricas europeas. Además, estos conjuntos han demostrado gran resiliencia y adaptabilidad para albergar programas sociales y culturales. Por tanto el estudio se focaliza en dos redes concretas de museos ubicados en antiguos edificios industriales que llamaremos Fábricas Culturales: los pertenecientes al museo de la Ciencia y la Técnica de Cataluña y los pertenecientes a la asociación del Ruhr. El artículo forma parte de una investigación que contribuye a poner en valor las políticas territoriales y urbanas que se realizan en áreas industriales degradadas, previo a la inauguración de museos. La clave del éxito de esos espacios reside no tanto en el propio objeto, como en la gran transformación urbana que la planificación permite. Constituyen ejemplos de renombre el Guggenheim de Bilbao o la intervención SUSAS en Shanghái. 


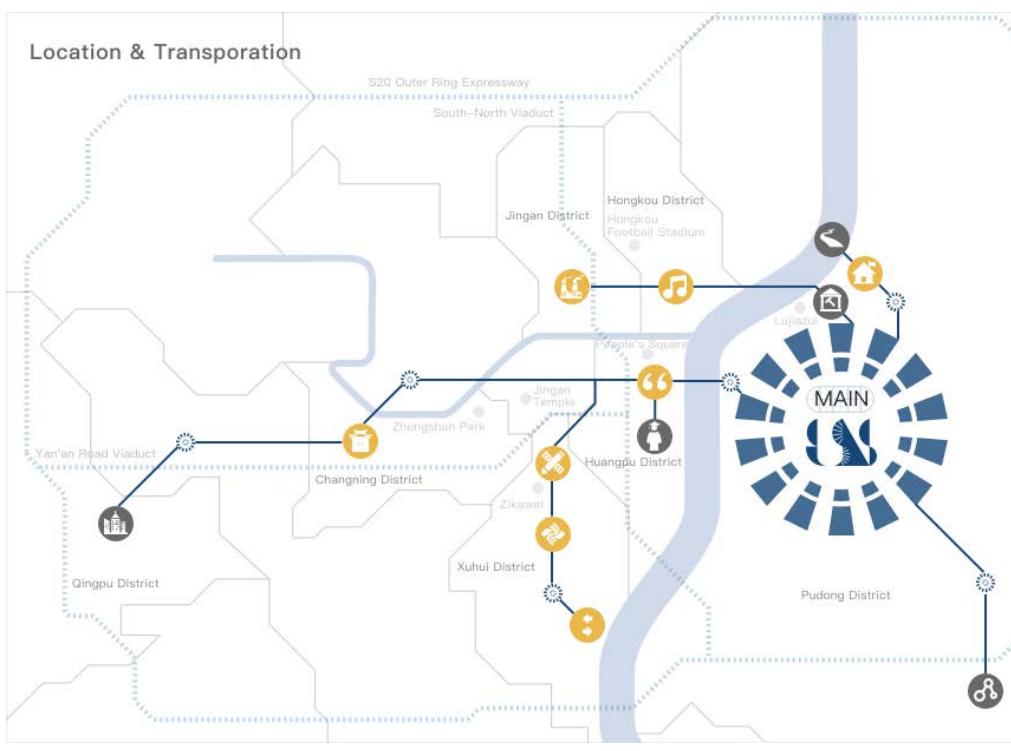

Este último caso incorpora nuevos conceptos, como la discontinuidad. Para los curadores de SUSAS 2017 (Shanghái Urban Space Art Season), el problema principal de diferentes tejidos urbanos o territoriales, entre los que se incluyen las áreas industriales, es su falta de conectividad. Para corregirlo se plantean diferentes propuestas de reconversión urbana, no solo en las inmediaciones del recinto sino en toda la ciudad ${ }^{51}$, poniendo el foco también en otros casos nacionales e internacionales.

Fig. 01 Diagrama de localización de los diferentes lugares vinculados a la exposición SUSAS 2017, incluyendo la sede en un antiguo silo de 80.000 toneladas en Minsheng Port, Pudong New Area, Shanghai. Fuente: http://www.susas.com.cn/EN-phone/location.html

\section{PLANIFICACIÓN REGIONAL EN DOS TERRITORIOS INDUSTRIALES EUROPEOS}

La conectividad de ciudades y territorios es una cuestión relevante, especialmente desde los siglos XIX y XX ${ }^{52}$. Actualmente sigue vigente la búsqueda de regiones conectadas como muestra la siguiente imagen del estudio regional para el Nuevo Ruhr. Si bien deben utilizarse diferentes mecanismos para promover conexiones territoriales, el factor cultural es un componente clave. Múltiples autores debaten en el contexto europeo sobre la regeneración cultural de áreas industriales ${ }^{53}$ con algunas voces críticas $^{54}$ sobre estos procesos que a menudo absorben grandes presupuestos con ganancias difíciles de cuantificar ${ }^{55}$. Es difícil aislar el papel regenerador de las transformaciones culturales en grandes metrópolis. Sin embargo, su efecto ha sido más acusado en áreas degradadas de ciudades intermedias, transformando no solo el entorno inmediato, sino la imagen de toda la ciudad e incluso la región. La descentralización de los motores culturales es un reclamo generalizado:

\footnotetext{
51 http://www.susas.com.cn/EN-phone/location.html

52 "The concept of modernity, as applied to 'Western' cities in the 19th and early 20th centuries, necessarily incorporates ideas about 'networked cities'", Dennis R. (2008). "Urban modernity, networks and places"

53 "Three examples of waterfront heritage zones case studies in Europe will be examined: Govan in Glasgow, Scotland with a long history of shipbuilding [...], Gdansk (Poland), [...] whose few remaining shipyards are operational, (some building luxury yachts), and Gothenburg in Sweden which is undergoing a master planning process that seems to ignore its shipbuilding heritage altogether". Gardiner, F. L., Kosmala, K. (2017) The Role of Cultural Planning Methodology in Contemporary Cultural Studies: The Case of Post-Industrial Cities.

54 This paper will demonstrate how this first model, while politically expedient and rhetorically seductive, was both theoretically unstable and practically unrealizable. Connolly, M. G. (2011) The 'Liverpool model(s)': cultural planning, Liverpool and Capital of Culture 2008

55 "Changing the mind-set of local residents was perhaps the IBA's greatest accomplishment_-particularly important during a time of economic restructuring". Labelle, J. M.(2001) Emscher Park, Germany, expanding the definition of a "park"
} 


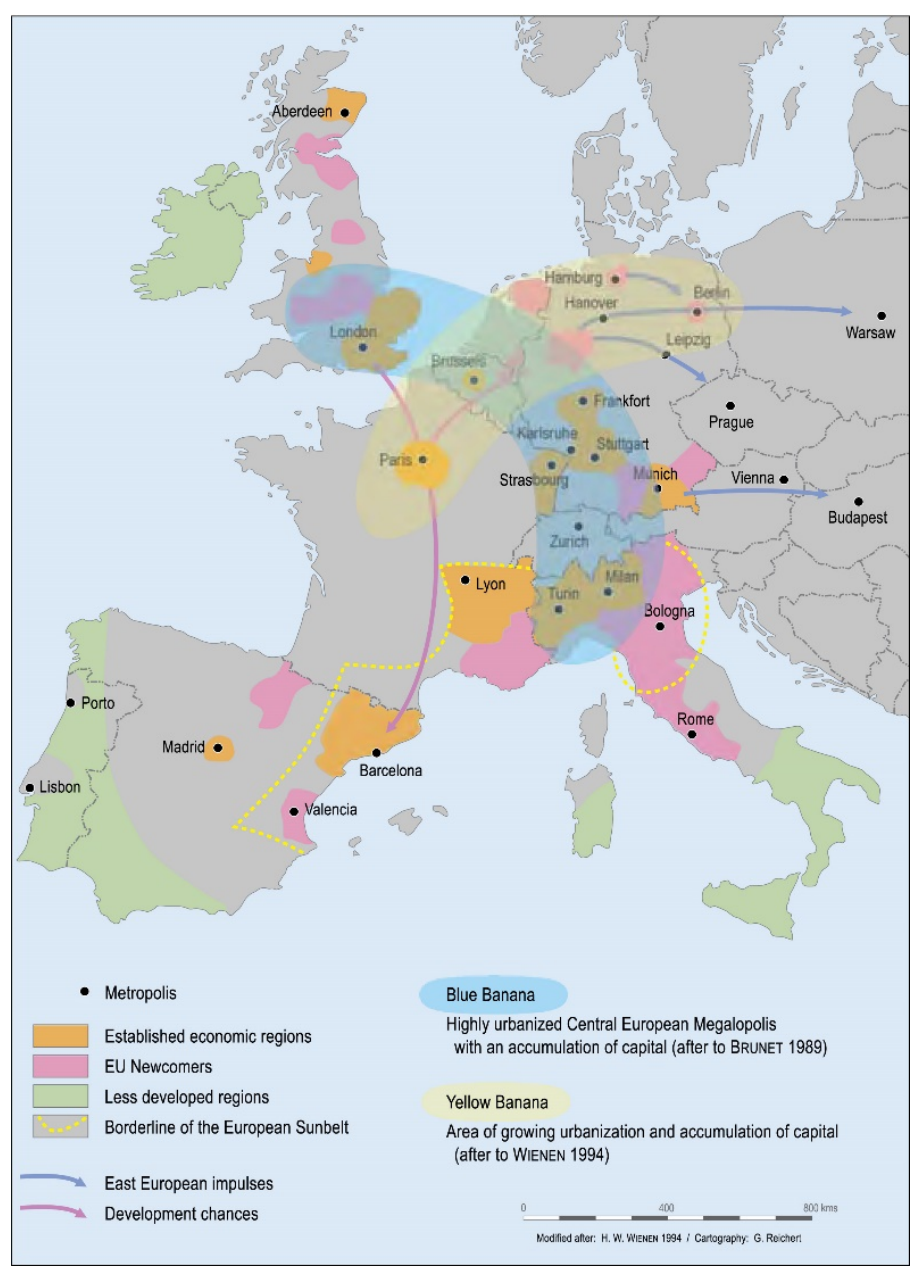

"Greater equality in distribution and integration of cultural provision and urban design, in order to prevent the reinforcement of existing geographical and cultural divides". Evans, G. (2001) Cultural Planning an urban renaissance?

Ahora bien, si se deben realizar operaciones culturales en áreas extensas, se debe analizar con precaución los lugares más propicios para ello. Seguramente ese es uno de los objetivos de planes como los que analizamos. En las nuevas políticas supranacionales se buscan áreas de oportunidad, lugares con mejor conectividad para una vez alcanzado el éxito redistribuir las conexiones a nuevos centros. Por ello es útil conocer la situación original y los esfuerzos previos de los dos territorios objeto de estudio en este artículo. Comenzaremos con una aproximación histórica a los inicios de la planificación regional de ambos territorios, con acento en lo que los hace relevantes. Desde el origen, durante la protoindustrialización, los recursos hídricos fueron fundamentales como motor energético. Más adelante se realiza un esfuerzo por comunicar estas zonas con los nuevos medios de transporte.

Fig. 02 Modelo Banana: un modelo estratégico geográfico de las regiones económicas europeas, en base a Wienen 1994, cartografía: Reichert. Fuente: Metropolis Ruhr, A Regional Study of the New Ruhr, Andreas Keil and Burkhard Wetterau, 2012.

Un análisis de la normativa territorial catalana, en el contexto de la industrialización, podría partir de 1836, cuando se instauran las Diputaciones en España. A partir de entonces, las redes de transporte se diversifican. En un primer momento, aparece una apuesta por la centralidad de Barcelona, de la que surge un esquema radial de conexiones. Pero más adelante podemos ver el cambio planteado en el Plan de carreteras provincial de Barcelona de Antonio de Arriete en 1847, donde destacan hasta 6 caminos radiales, y uno concéntrico que conecta de costa a costa el norte y el sur de Barcelona pasando por Vic e Igualada. 


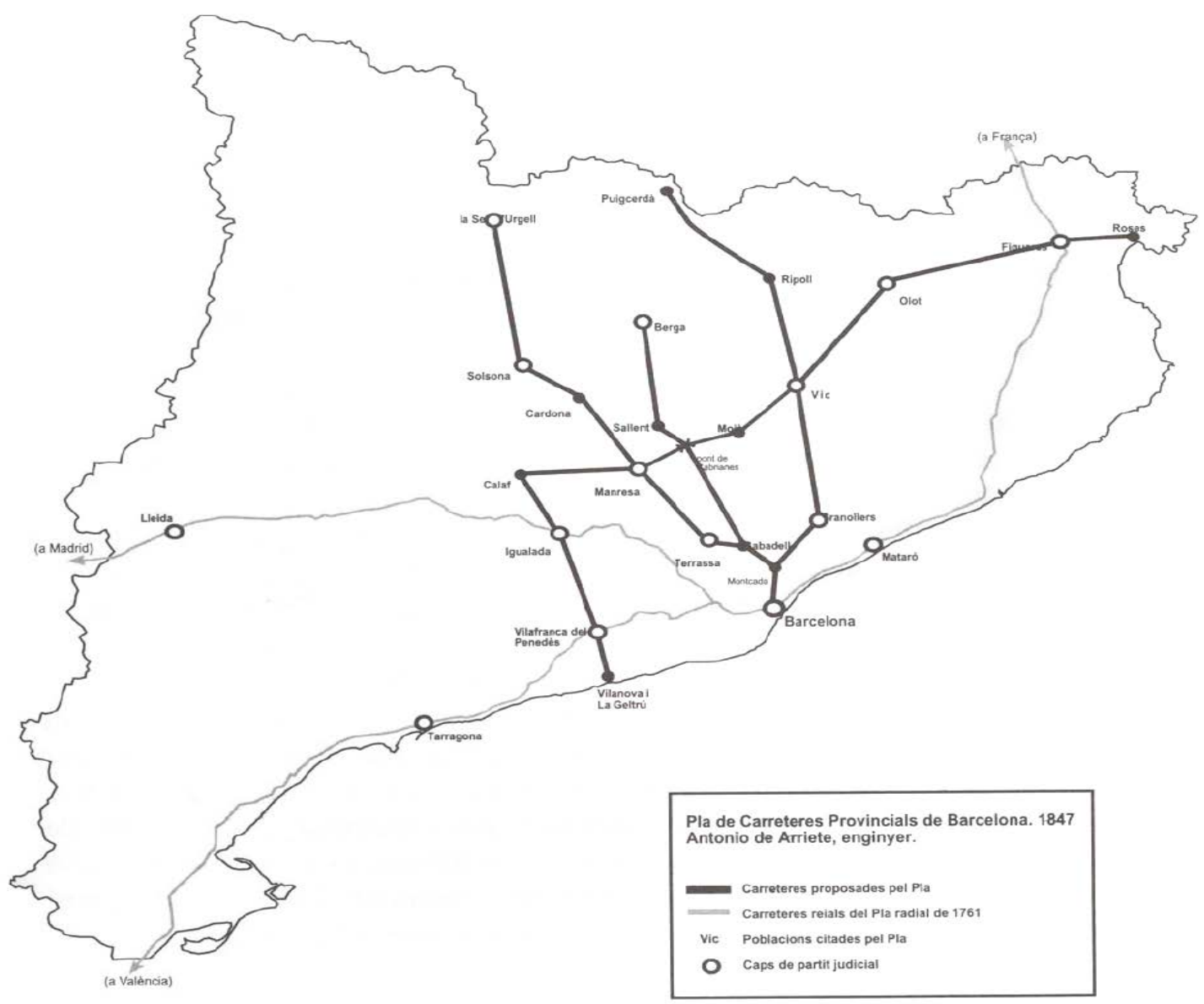

Fig. 03 Plan de Carreteras Provinciales de Barcelona, 1847, Antonio de Arriete. Fuente: ICGC.

Hasta 1935, destacan tres periodos que definen la construcción de la red de carreteras. El primero acaba con la Ley de Obras públicas de 1857. Es un periodo de pocas realizaciones, pero supone un inicio en el financiamiento y construcción moderno de las obras públicas. El segundo comprende desde la "Ley decreto de 1857, hasta la promulgación del cuarto plan General de Carreteras". ${ }^{56}$ En esta época el ferrocarril cobra mayor importancia que la red de carreteras. Por último, el tercer periodo comprende desde la Mancomunidad de Cataluña (1914 a 1924) hasta la Generalitat republicana (19321939). Al aparecer el automóvil, las carreteras vuelven a primar sobre el ferrocarril.

La imagen siguiente, corresponde al primer periodo. El sistema de carreteras radial aún no se percibe, sino más bien cierta ramificación de los caminos estatales o reales. En este momento, "la burguesía catalana, básicamente barcelonesa, protagonista de la industrialización, apoya la tarea de construcción viaria llevaba a cabo por la Diputación, pero pronto depositó una mayor confianza en el ferrocarril". ${ }^{57}$ Como vemos en el plano, Terrassa se beneficia de la futura construcción viaria.

${ }^{56}$ Font i Garolera, J. (1993) “La formació històrica de la xarxa de carreteres a Catalunya (1761 -1935)”

57 Navas T. (2008) “Modernitzar el territori: la planificació i construcció de la xarxa de carreteres de l'àrea de Barcelona" pág. 123 (Traducción propia) 


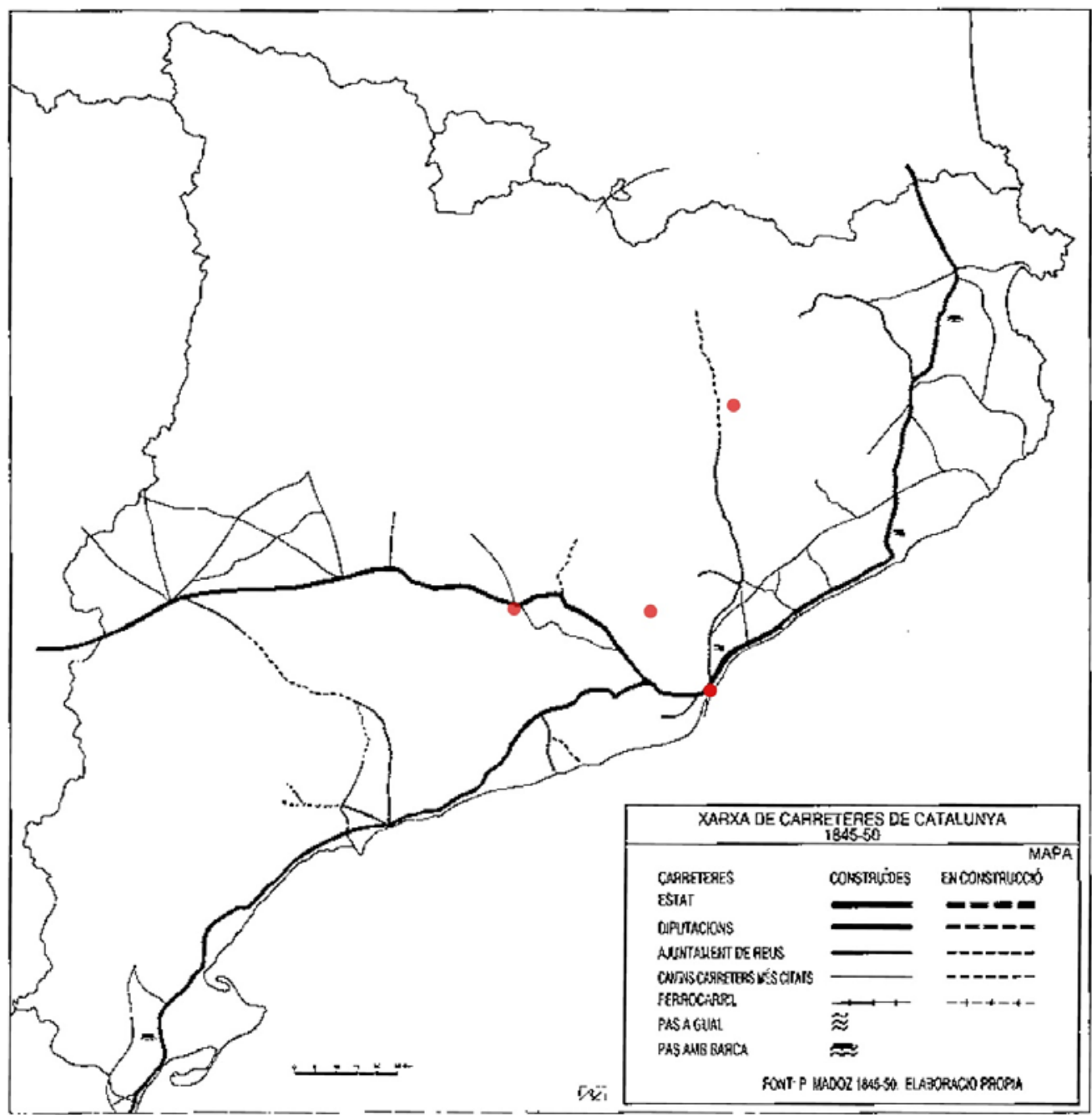

Fig. 04 Red de carreteras de Cataluña, 1845-50. Fuente: ICGC.

Del segundo periodo destaca el estudio realizado por Melchor de Palau (1890) "Carreteras provinciales de Barcelona: estudio histórico-critico". Este trabajo es una muestra de la relevancia que la reflexión y planificación del territorio va tomando. "En el caso de la provincia de Barcelona, Palau elabora en 1879 el Plan de carreteras provinciales con una extensión de casi $1.000 \mathrm{~km}$, que es todo un referente en la formación de una red local". ${ }^{58}$ Podemos comprobar el cambio producido en pocos años, comparando la imagen anterior con ésta. En este momento, tanto Terrassa como Manlleu, pasan a estar integradas en la red de comunicaciones nacional; si bien muchos municipios del interior, sobre todo los próximos al Pirineo, permanecen incomunicados. Una lacra que Palau compara con el sistema ramificado de los árboles: la falta de ramificaciones produce que no llegue la salvia a todas las partes, en este caso, del territorio.

Si bien esta desconexión es parcial, ya que diferentes trazados históricos atraviesan el territorio. Esos trazados, junto a otras características geográficas, determinan la evolución de las diferentes redes: postales, de carreteras o de ferrocarril. Primero se modernizan los "ejes básicos que coinciden con los caminos naturales"; ${ }^{59}$ luego se generan ejes secundarios en torno a los nudos centrales, y por último se da servicio a las zonas más aisladas. Sobre la relación entre las redes de

\footnotetext{
${ }^{58}$ Navas T. (2012) “Crecimiento Urbano, red de carreteras y Tranvía Eléctrico en el Área de Barcelona”.

59 Font i Garolera, J. (1993) “La formació històrica de la xarxa de carreteres a Catalunya (1761 -1935)”
} 
ferrocarril y el desarrollo urbano en Cataluña cabe destacar las tesis doctorales de Domingo (1986) y Álvarez-Palau (2015). En algunos casos estas infraestructuras favorecen la aparición de intercambios comerciales, mientras en otros, aparece primero el foco comercial o productivo y esto incentiva la creación de redes de infraestructuras. En cualquier caso, es un proceso recíproco, que debe planificarse con precaución.

En 1935 aún queda mucho por hacer por lo que se suceden dos estudios. Uno estudia el territorio desde el punto de vista de sus vocaciones; mientras que el otro se plantea atendiendo a las infraestructuras: en primer lugar el Regional Plan de Rubió i Tudurí (1932-1934) y en segundo, el Plan General de Obras Públicas de la Generalitat de 1935, bajo el liderazgo de Victoriano Muñoz Oms. El primero propone una búsqueda de los componentes que definen el territorio, con el objetivo de sacar el máximo partido del mismo. Lo coordinan los hermanos Rubió i Tudurí, quienes analizan desde un punto de vista crítico, como se ha organizado el territorio con anterioridad. Sin duda, el componente que origina las primeras fábricas de algodón, está totalmente ligado al territorio. Los ríos tienen un papel muy importante, pues ofrecen energía y conexión paisajística y de trazados históricos, frente a la orografía más accidentada del resto del territorio.

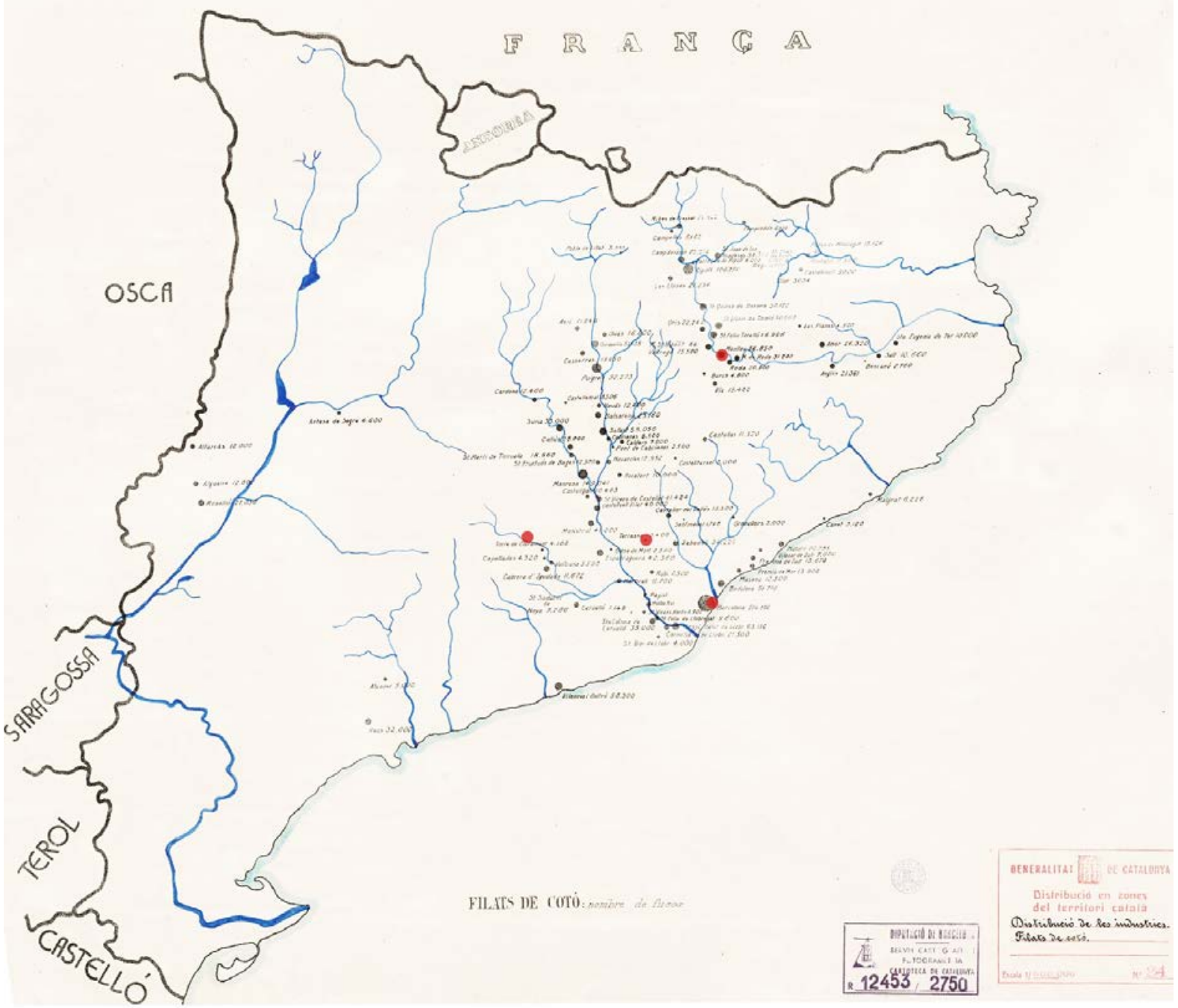

Fig. 05 Principales ríos y fábricas de tejidos de algodón en Cataluña, 1932, Rubió y Tudurí. Fuente: ICGC. 
Otro documento de singular relevancia histórica es el Plan General de Obras Públicas de la Generalitat de 1935. Lo realiza un equipo de seis técnicos y pretende ser una herramienta para organizar el territorio, una vez conocidos los déficits del estudio anterior y a falta de más datos por conocer. Todos estos planes muestran su afán de gestión territorial. Como indica Vallés i Pujals, presidente de la Diputación de Barcelona (1917-1924): “Es menos malo seguir un plan equivocado que ir obrando sin ningún tipo de plan". ${ }^{60}$ Se incluye un decálogo de objetivos de base social y equitativa. Todos ellos hacen hincapié en la redistribución de la riqueza del país, el equilibrio entre comarcas de interior y de costa, y el fortalecimiento de nuevos núcleos. Además se incluye cierta base científica, en la búsqueda de criterios que permitan rigor en la toma de decisiones, un plan flexible y duradero. Este primer plano es una muestra de sus objetivos; representa la red de caminos generales, con una malla multi-nodal que desmonta el efecto radial de Barcelona.

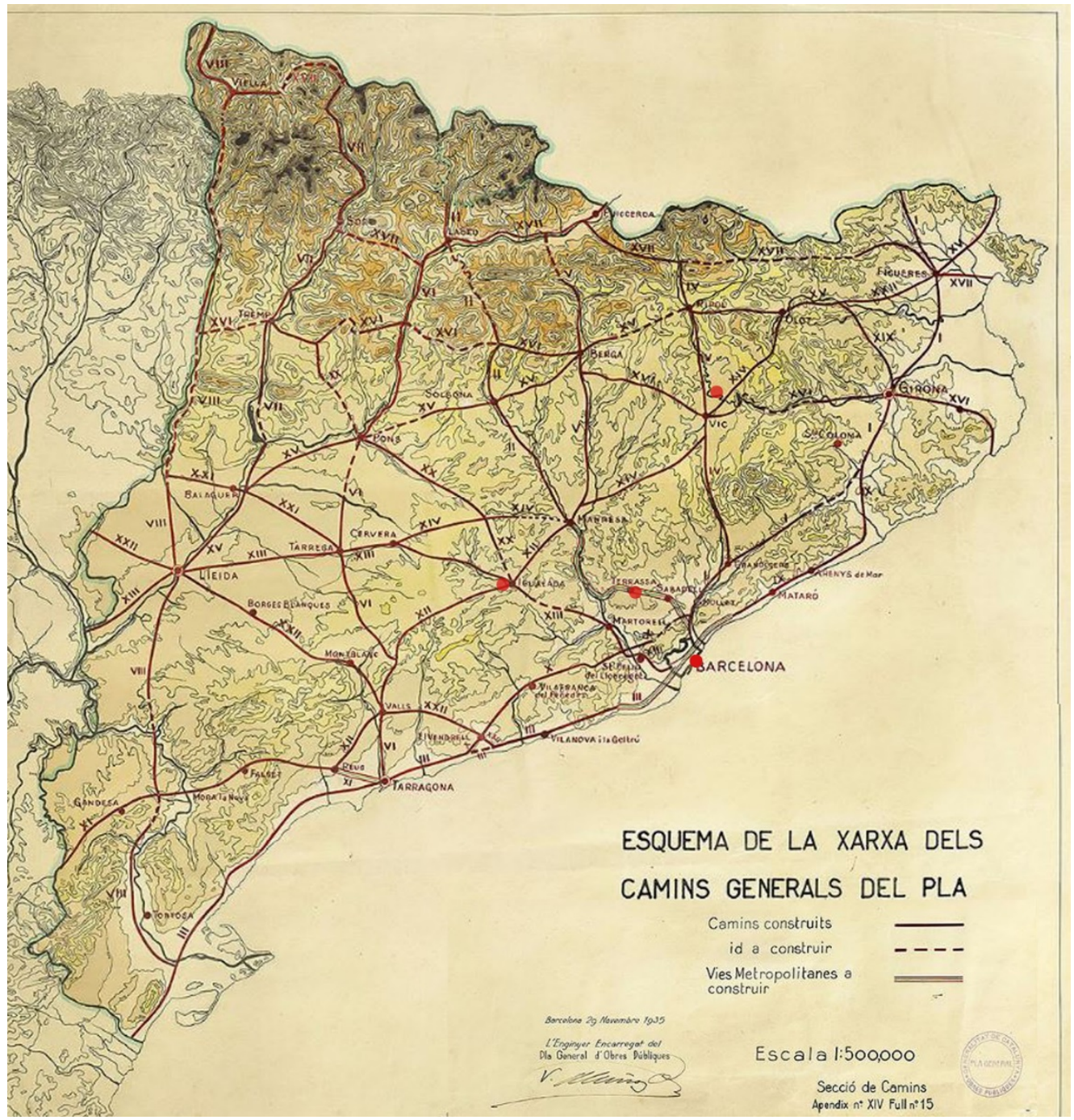

Fig. 06 Esquema de la red de caminos generales del Plan General de Obras Públicas, 1935, Victoriano Muñoz Oms. Fuente: ICGC.

Se empieza estableciendo bases estadísticas y cartográficas. A continuación, se realizan mapas de tanteo, seguidos de otros definitivos con rectificaciones y una última fase de información pública. Cabe destacar que el plan se realiza en un

${ }^{60}$ Carreras i Puigdengolas, J. M. Bernat i Falomir, J. y Riera i Figueras P. (2009) "El Pla general d'obres públiques de 1935: política, infraestructures i territori" p. 114 
contexto histórico convulso. Una de las reclamaciones ciudadanas es el acceso al agua potable; a lo que el gobierno de la Mancomunidad responde: "ningún pueblo sin agua". ${ }^{61}$ Por ello es de vital importancia en este documento una planificación y gestión óptima de los recursos hídricos.

"Si bien no se llegaron a aprobar [...] como dijo su director, Victoriano Muñoz Oms, en el premio del libro que publicó en el año 1982: [...] "las tareas bien concebidas no permanecen nunca estériles, y así de ese Plan del año 1935, devinieron y se derivaron algunos otros remarcables: el Plano de aguas de Cataluña de 1957, el aprovechamiento integral del Ribagorçana, la Ponencia del Plan Nacional de Carreteras del año 1939, además de otras constataciones en materia de carreteras, teléfonos, etc., etc. y por lo que respecta al Plano de Caminos, muchas de sus propuestas se han ido realizando con el paso del tiempo". ${ }^{62}$

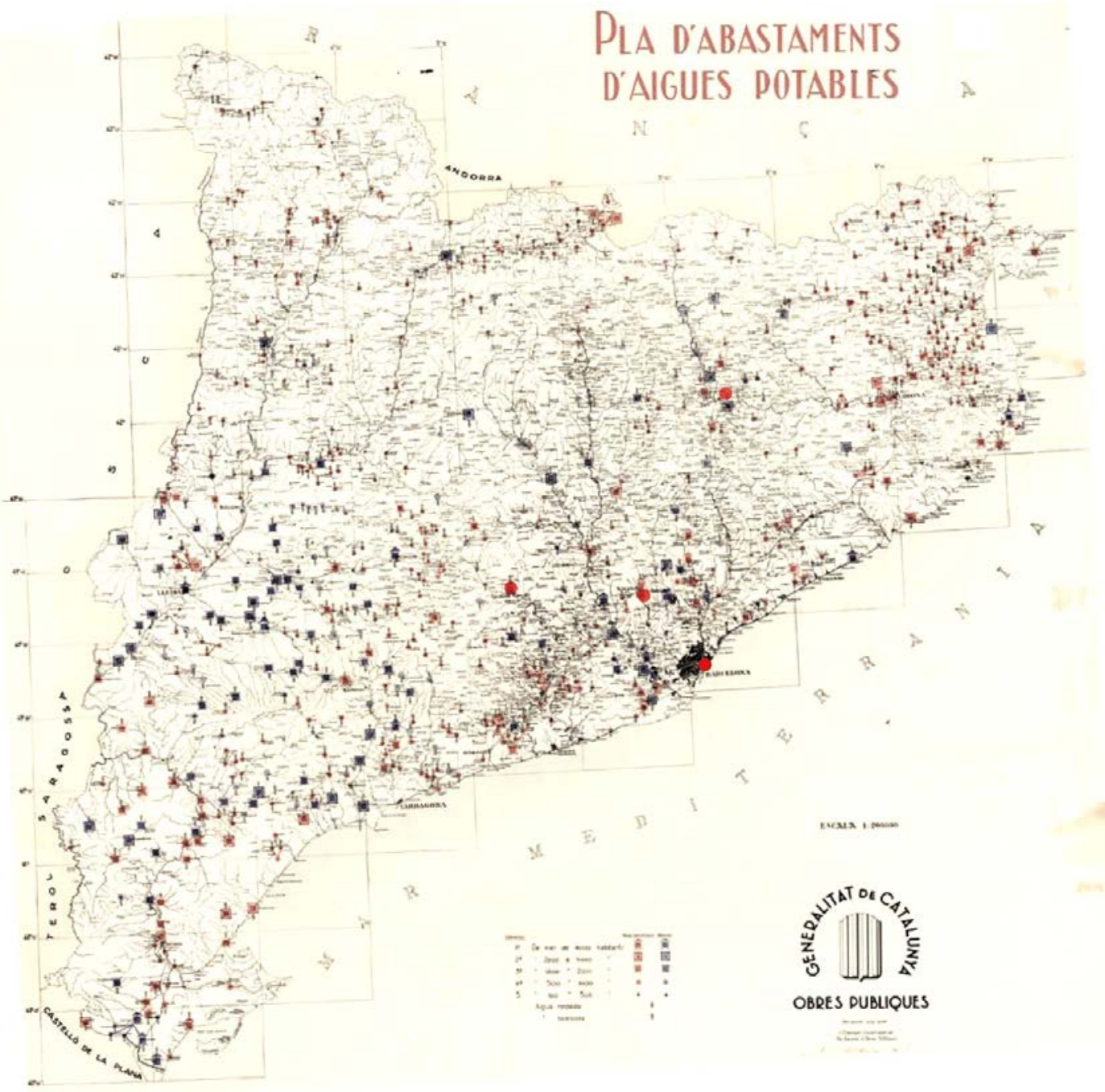

Fig. 07 Plan de Abastecimiento de Aguas Potables, 1935, Victoriano Muñoz Oms. Fuente: ICGC.

${ }^{61}$ Carreras i Puigdengolas, J. M. Bernat i Falomir, J. y Riera i Figueras P. (2009) "El Pla general d'obres públiques de 1935: política, infraestructures i territori" p. 114

${ }^{62}$ Carreras i Puigdengolas, J. M. Bernat i Falomir, J. y Riera i Figueras P. (2009) "El Pla general d'obres públiques de 1935: política, infraestructures i territori" p. 65. 
Hemos podido verificar la innovación en el interés policéntrico y regional de la planificación histórica en el contexto catalán. A continuación profundizamos en los planes que se realizaron en la región del Ruhr en la misma línea regionalista, innovando a escala nacional. A pesar de sus orígenes como estados políticamente independientes, la región del Ruhr supo aunar esfuerzos para fomentar procesos industriales bajo la ilustración que abanderaba la sociedad prusiana. Los acuerdos en temas de impuestos y la alta calidad del carbón de la zona, la convierten en un centro industrial muy importante para la economía europea. No solo se beneficiaba de esa materia prima Alemania, sino también vecinos como Francia, Luxemburgo, Países Bajos y Bélgica. Esta región destaca por la confluencia de grandes ríos como el Ruhr y el Rin con otros menores como el Lippe y el Emscher. Es por tanto una zona rica en recursos naturales, que se refuerza progresivamente con una extensa y compleja red de infraestructuras de transporte que cuenta además con varios canales industriales ${ }^{63}$.
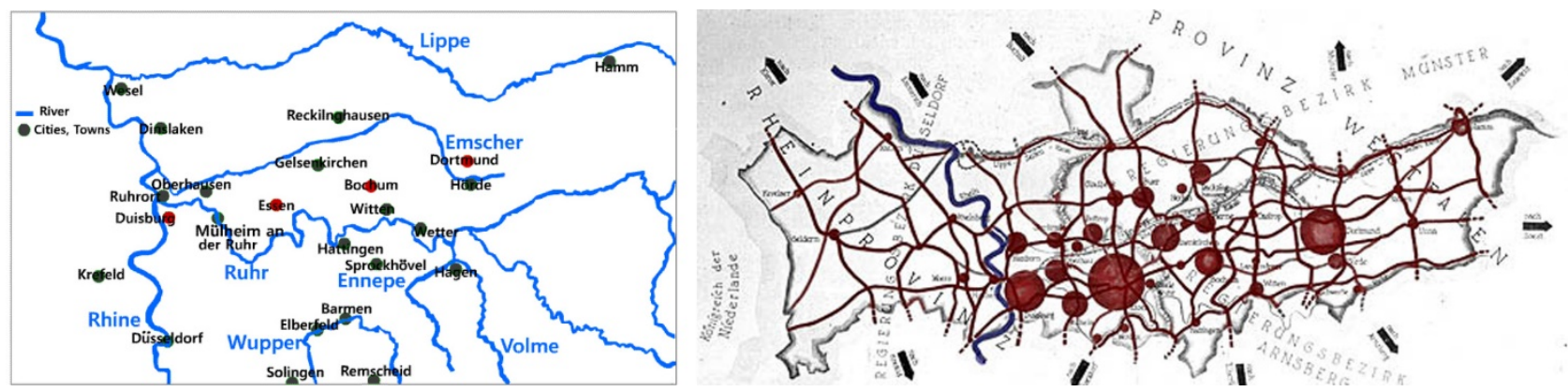

Fig. 08 Ciudades y ríos en la región del Ruhr, 1800 apróx. 1952, Pounds pp. 35 y 39. Fuente: Roh, Y. H. (2007) The Rise of the Ruhr Area, Germany's Industrial Heartland, in the 19th Century.

Fig. 09 Plan de carreteras del Ruhr (Plans for the Ruhr under Siedlungsverband Ruhrkohlenbezirk 1920-1934). Fuente: Roh, Y. H. (2007) The Rise of the Ruhr Area, Germany's Industrial Heartland, in the 19th Century.

La superposición de los planos anteriores que corresponden a las ciudades y ríos en la región del Ruhr en 1800 apróx. y el Plan de carreteras del Ruhr en 1925, junto a la siguiente que muestra las vías Férreas de la región del Ruhr, 1930 apróx. (Pounds $1952^{14}$ p.213); permite comprender las intenciones por generar sinergias entre las ciudades que forman parte de un territorio común más allá de los límites políticos. Estos planes no buscan una mejor conexión para una sola ciudad de la que parte una red radial, sino que al igual que en Cataluña, se busca una interconexión policéntrica. Esta visión supramunicipal, es reforzada por Schmidt, R., visionario e influyente urbanista, que asienta las bases de la planificación regional del área del Ruhr mediante el "Memorando de principios para establecer un plan general en el distrito de Dusseldorf" (1912) y acaba por convertirse en el primer director de la RVR, Regionalverband Ruhr (Asociación Regional del Ruhr) y la Spitzenverband für Städtebau und Landesplanung (Asociación general para la planificación urbana y planificación estatal). En este proceso tuvieron un papel fundamental la cooperación y los procesos informales, así como el desarrollo conjunto de acciones entre los diferentes municipios de la región ${ }^{64}$.

${ }^{63}$ Roh, Y. H. (2007) The Rise of the Ruhr Area, Germany's Industrial Heartland, in the 19th Century.

${ }^{64}$ Der Regionalverband Ruhr informiert: Pressemitteilungen. Robert Schmidt - ein früher Visionär für die Zukunft und die Gestaltung des Ruhrgebiets (04-12-2014) 


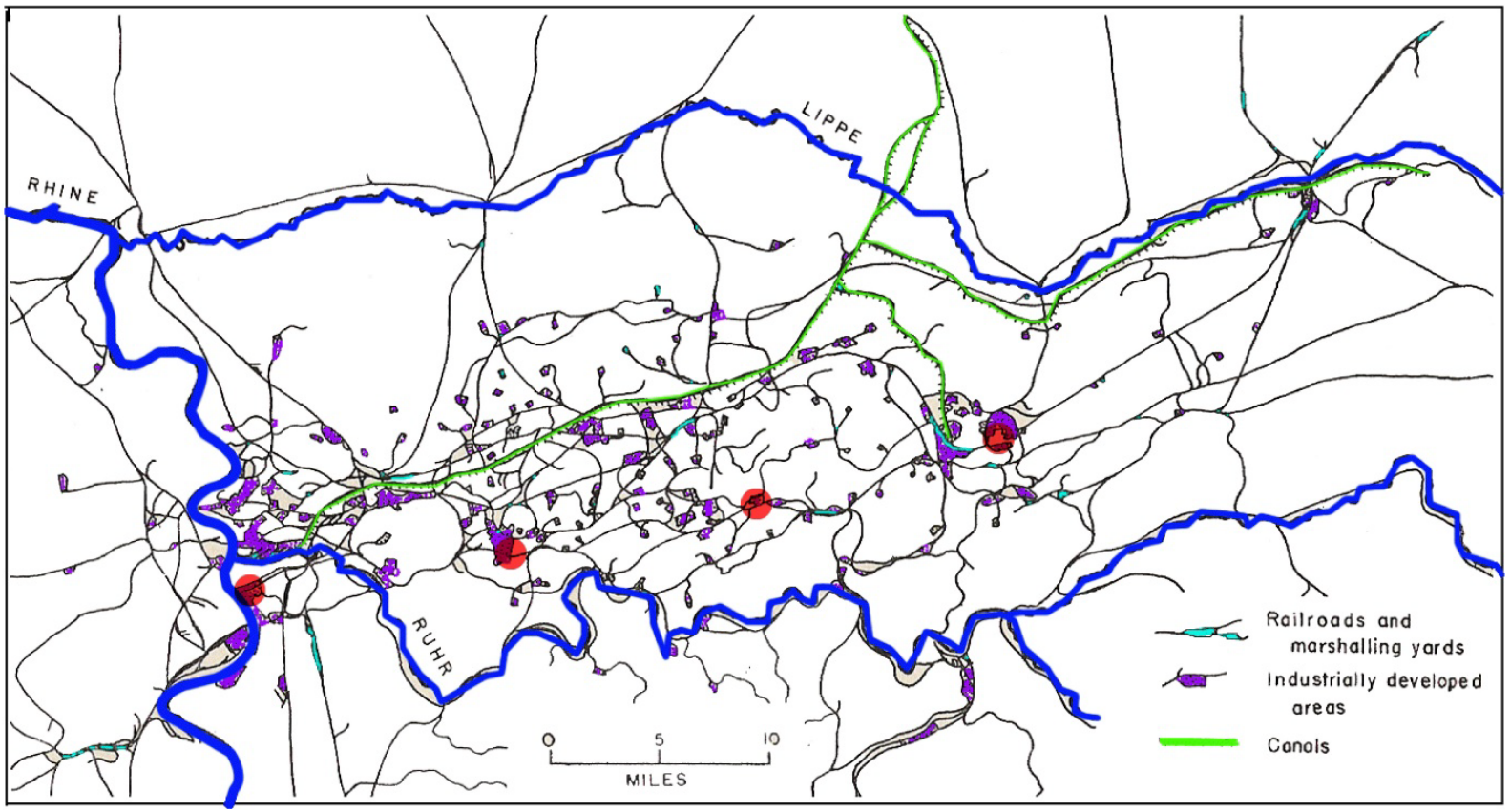

Fig. 10 vías Férreas de la región del Ruhr, 1930 apróx. (Pounds 195214 p.213). Fuente: Der Regionalverband Ruhr informiert: Pressemitteilungen. Robert Schmidt - ein früher Visionär für die Zukunft und die Gestaltung des Ruhrgebiets (04-12-2014)

Autores como Kunzmann (2003), iniciador e impulsor del desarrollo de las ciudades y regiones alemanas a través de las industrias culturales y creativas, o Schmidt y Buehler (2017) reconocen que "los orígenes de la planificación regional alemana se remontan a principios del siglo XX cuando los municipios, tanto del Ruhr, como del área metropolitana de Berlín, comienzan a organizarse entre sí de manera voluntaria”. En concreto en 1920 diferentes distritos de la región del Ruhr se unen para preservar espacios verdes, por el riesgo del crecimiento de las áreas industriales. Esa comisión conocida como Grünflächenkomission crea "lo que puede ser considerado como la primera planificación regional de Alemania" según W. Hoffman (1981), dando lugar a la Siedlungsverband Ruhrkohlenbezirk (SVR, Autoridad para la Planificación Regional del Ruhr). Estos órganos administrativos y la gestión conjunta de amplios territorios favorecen en un futuro la toma de acciones conjuntas para salvaguardar el patrimonio industrial y transformar la actividad productiva hacía sectores terciarios. Frente a ciudades aisladas, una región policéntrica interconectada mediante infraestructura física, pero también administrativa incrementa la resiliencia del territorio, permitiendo la rápida adopción de soluciones creativas frente a nuevos retos.

En 1965 se confirman las tendencias descentralizadoras en Alemania con la Ley Federal de Planificación Espacial que promueve la organización del país de una forma equitativa. Estas normativas son respaldadas por políticas que promueven la redistribución de recursos hacía "zonas rurales remotas (Bundesausbaugebiete), la frontera con la antigua Alemania del Este (Zonenrandgebiet), y, más recientemente, áreas mineras deprimidas en la región del Ruhr y Saar". Posteriormente las políticas de integración de la Unión Europea también refuerzan el desarrollo inter-regional de esta zona. Como resultado, la planificación alemana continua "con un particular énfasis en la descentralización"65.

65 Schmidt, S. y Buehler, R. (2017). The planning process in the US and Germany: A Comparative Analysis. 


\section{EVENTOS Y REDES CULTURALES EN DOS TERRITORIOS INDUSTRIALES EUROPEOS}

La mentalidad integradora que aboga por la planificación a gran escala, ha permeado de los planes de transporte o redes naturales, a los proyectos culturales propios de las inquietudes de nuestra época. Antes de profundizar en los casos de estudio, conviene revisar los referentes de las redes culturales-industriales ${ }^{66}$. En 1967 se crea la primera red de espacios patrimoniales del periodo industrial: Ironbridge Gorge Museum Trust, formada por 35 espacios históricos, 10 de ellos museos. En 1978 nace el TICCIH o Comité Internacional para la Conservación del Patrimonio Industrial, con motivo de la III Conferencia Internacional sobre la Conservación de Monumentos Industriales, que se celebra en Suecia. Dos años más tarde el TICCIH se configura como consultor de la UNESCO para la selección de los monumentos, sitios y paisajes de la industria y de la industrialización. En 1990 se establece la red de museos industriales catalana, el sistema territorial del mNACTEC. Entre 1989 y 1999, el estado federal de Renania del Norte-Westfalia, el más poblado de Alemania, organiza la Exposición Internacional de la Construcción (IBA) del Parque Emscher con el objetivo de convertir las industrias en proceso de abandono, en una red regional de espacios culturales y naturales. En 1999 se consolida la Red Europea de Patrimonio Industrial (ERIH) para promover y difundir este patrimonio en Europa, incluyendo nuevos recorridos temáticos internacionales. En la actualidad, cuenta con más de 1.300 espacios en 45 países.

Los procesos para establecer y gestionar este tipo de redes son complejos y requieren de una fuerte inversión estatal, ya que los municipios no pueden asumir este tipo de intervenciones de gran escala. Por otra parte el retorno es difícil de cuantificar y se vincula a otros factores, como el posicionamiento de la región a escala internacional y la autoestima de la población local. Ambos factores son relevantes en un clima de migraciones, tanto de personas como de capital, hacía grandes ciudades o ciudades intermedias bien interconectadas. Tras la decadencia de las industrias contaminantes en Europa, crece el desempleo y las desigualdades sociales. Frente a la diversidad de actuaciones posibles, la regeneración cultural ha sido una alternativa extendida. Es interesante pues reflexionar cómo han evolucionado en los últimos 30 años dos actuaciones emblemáticas en el contexto europeo, IBA Emscher Park y el sistema territorial del mNACTEC.

Como afirma Sabaté (2003), "si bien la mayor parte de los planes de ordenación del siglo XX hicieron hincapié en la dinámica poblacional y en el desarrollo industrial, en el siglo XXI las propuestas de ordenación territorial de mayor interés estarán basadas en un nuevo binomio: naturaleza y cultura." Así ha sucedido tanto en Barcelona como en el Ruhr. En el primer caso, "a raíz de los Juegos Olímpicos se produjo un cambio de orientación urbanística de la ciudad hacia proyectos de reconversión de suelo industrial" (Tatjer, 2006). A pesar de grandes pérdidas patrimoniales (Caballé, F. 2010), el reclamo de intelectuales, ingenieros, historiadores, artistas y comunidades locales permitió dar el empuje necesario para proteger y recuperar elementos del patrimonio industrial de Barcelona para fines cívicos. Monclús (2006:xviii) también destaca la influencia de la cultura en el urbanismo reciente "Así como la economía cultural se establece a partir de 1970 primero en las ciudades norteamericanas y luego en otras metrópolis occidentales, el planeamiento convencional dio paso al Urbanismo cultural y estratégico. [Los museos, como] las olimpíadas, son tan susceptibles de convertirse en meras políticas de imagen como de generar considerables beneficios económicos y sociales."

La descentralización en las redes culturales catalanas está en gran medida influenciada por el patrimonio industrial. De hecho, los museos nacionales catalanes siempre habían estado en Barcelona capital, hasta que en 1984, bajo la dirección de Eusebi Casanelles, se establece el museo de la Ciencia y la Técnica de Cataluña en Terrassa y seis años después la Ley de Museos lo declara Museo Nacional. “La Ley de museos de 1990, en su prefacio dice: Los museos nacionales [Catalanes] encabezan la articulación del sistema museístico de Cataluña [...] y extienden su servicio a todo el País" (Casanelles, 2013:32). De hecho el lema del sistema territorial del mNACTEC es: Un museo nacional extendido por todo el país. Podemos comparar a continuación la localización de las Instituciones Culturales Nacionales Catalanas, como la Biblioteca de Cataluña de 1914, el Museo Nacional de Arte de Catalunya de 1929, el Archivo Nacional de 1984 o el Museo de Arqueología de Cataluña de 1990, frente a las sedes del sistema del mNACTEC en la provincia de Barcelona. Todo ello

${ }^{66}$ Romero, K (2017) [Fábricas y Redes] Culturales. Elementos patrimoniales estratégicos para organizar el territorio 
sobre un plano histórico de Rubió y Tudurí de 1932, que muestra la distribución de zonas del territorio catalán, manipulado para mostrar los límites de la provincia de Barcelona.

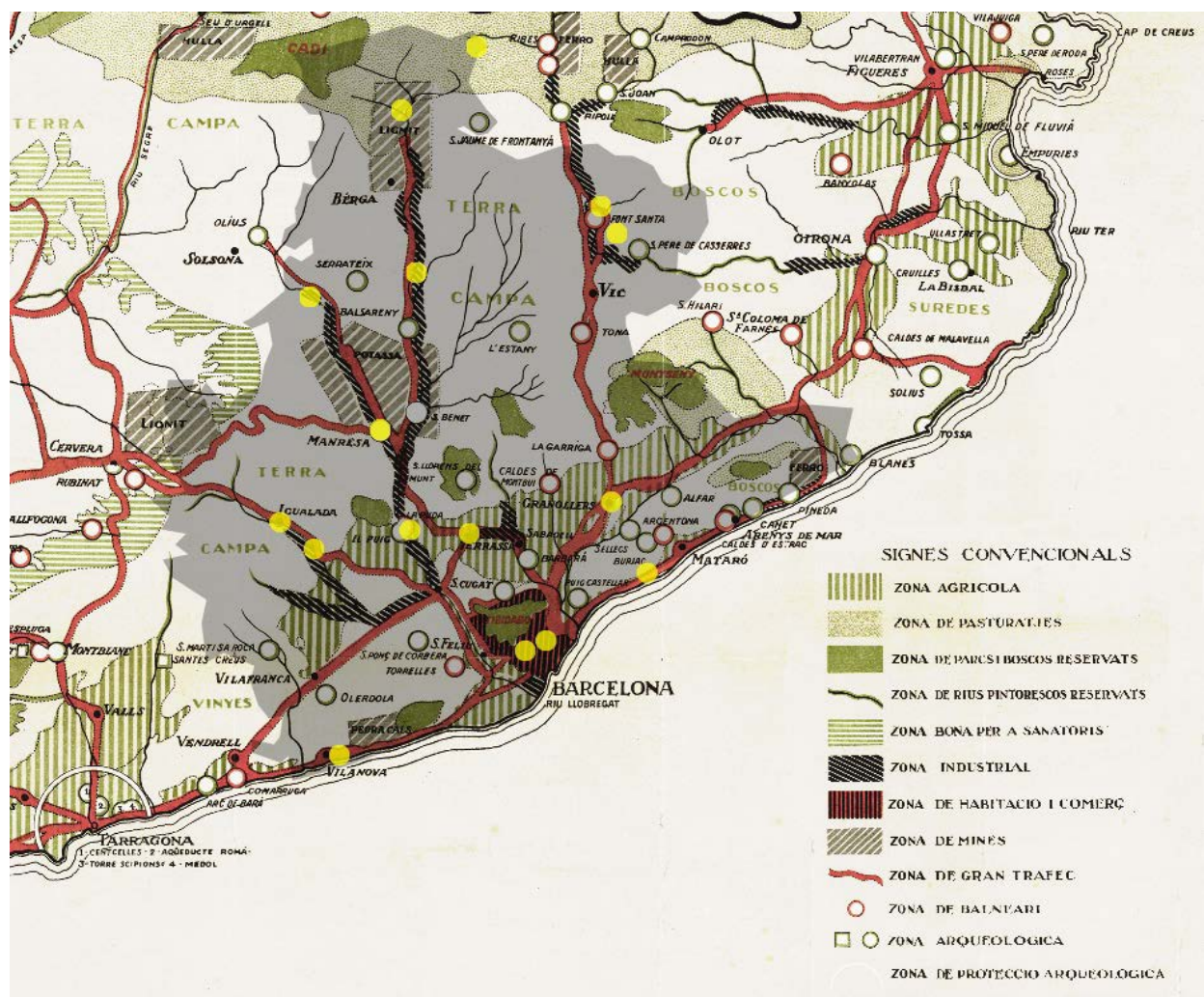

Fig. 11 Localización de las Instituciones Culturales Nacionales Catalanas. Elaboración propia en base a mapas de Catalunya (Rubió y Tudurí, 1932 y actual). Fuente: ICGC.

Las relaciones entre los centros del sistema territorial del mNACTEC es variable en función de la temática, la propiedad o tamaño del centro y la proximidad entre los mismos. Cabe destacar una disposición no radial, con centros en poblaciones más grandes próximas a la costa y más pequeñas los ubicados en el interior. En cuanto a los tipos de centro, se opta por una evolución del concepto de redes distribuidas como las de internet, donde, tal como enuncia M. Castells: "nadie es el líder" (Casanelles, 2007:11). Para el mNACTEC se tiene en cuenta que "el liderazgo en un sistema es necesario si se quiere realizar una política de acciones transversales" (Casanelles, 2007:11). En el caso del mNACTEC los museos que ejercen este liderazgo se agrupan en Museos Sede y Museos Sección. Estos últimos están acreditados como museos en el registro de la Generalitat de Cataluña. Se trata del Museu Molí Paperer de Capellades, Museu de la Pell d'Igualada i Comarcal de l'Anoia, Museu del Suro de Palafrugell, Ecomuseu Farinera de Castelló d’Empúries, Museu de les Mines de Cercs y el Museu industrial del Ter en Manlleu. Todos ellos son los encargados de coordinar el conjunto, junto a los Museos Sede, que son propiedad de la entidad autónoma del Museo de la Ciencia y la Técnica: el mNACTEC de Terrassa y el Museu Colònia Sedó d'Esparraguera. El resto son museos colaboradores, recibiendo ayudas de los centros mayores. 


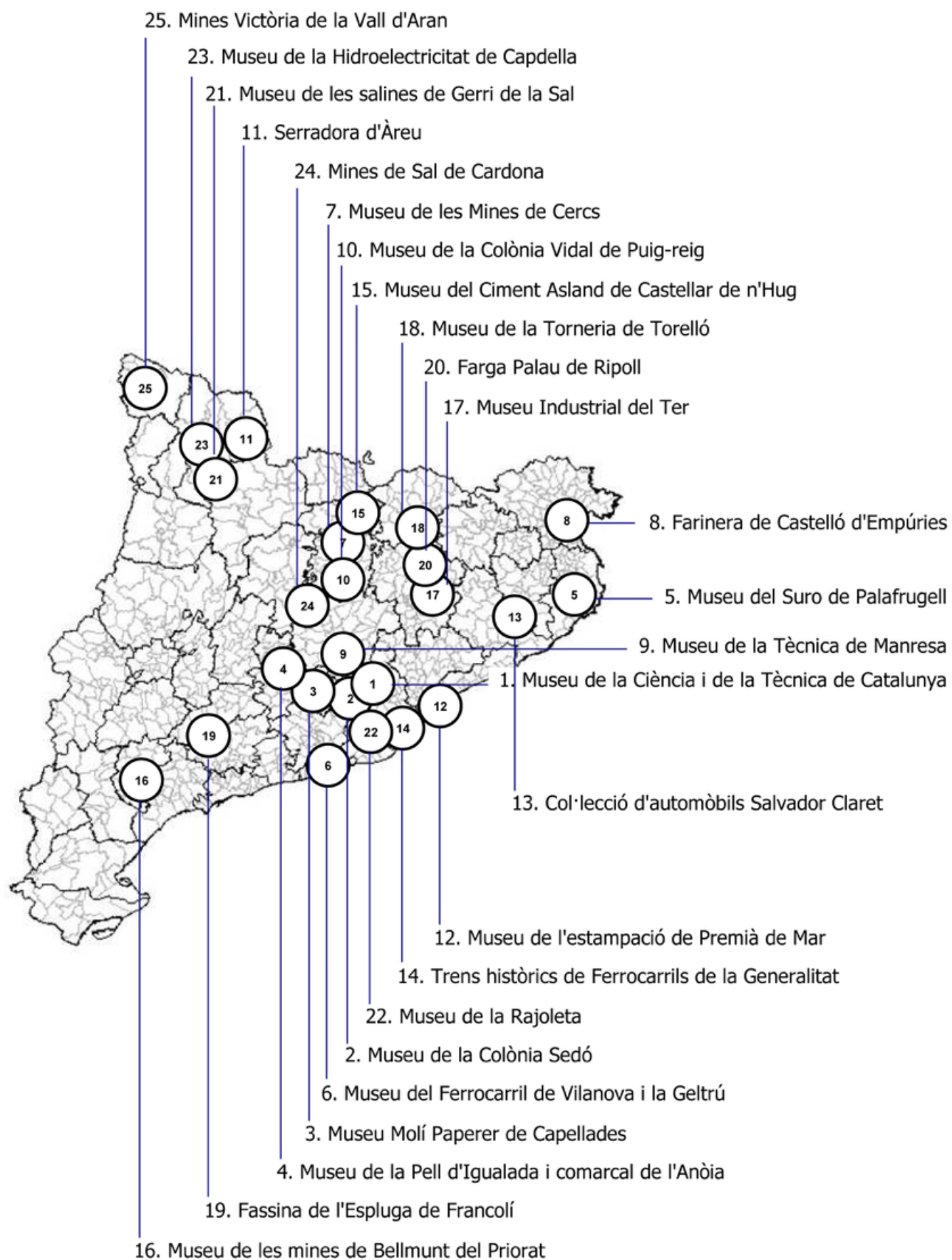

Fig. 12 Miembros del sistema territorial del mNACTEC. Fuente: Casanelles, 2007:30.

Las leyes que rigen este sistema se traducen en una serie de programas comunes para todos los miembros, obligatorios y opcionales. En cuanto a los primeros incluyen imagen institucional y comunicación; exposición y difusión; conservación e investigación y acción educativa. Esto incluye un logo para cada sede y un formato editorial para reforzar la importancia de las publicaciones del sistema. Además, cuentan con tickets y exhibiciones compartidas, así como con la conexión directa a través de las páginas web de los miembros del sistema. En cuanto a los programas opcionales encontramos: paisaje y rutas industriales; turismo cultural; ciencia, innovación y medioambiente. 
Por su parte, el Plan General del Paisaje de Emscher 2010, aprobado en 2005 y siguiendo el proyecto IBA 99 implica veinte ciudades, dos distritos rurales, tres administrativos, el gobierno federal y otros agentes. IBA se organiza como foro internacional para recabar ideas de renovación ecológica y cultural de zonas industriales degradadas. Su misión fue alcanzar en 10 años la revitalización urbana de la cuenca del Ruhr y el río Emscher a través de un concurso de proyectos seleccionados por consejos con representación de las autoridades locales, estatales, industria, el sector privado, profesionales, grupos ambientalistas, universidades y ciudadanos. Además de conformar una agrupación regional, permite posicionarlo como foco de inversión de cara a financiación o inversiones externas; todo ello a coste de una ardua organización interna. En 1980 la región se enfrentaba a unas tasas de desempleo del 15\%, con una degradación social y ambiental evidente. La apuesta por la innovación de la región es otra seña de identidad del proceso de regeneración cultural. Se promueven diversos concursos de ideas, ya que se necesitaban soluciones creativas ante una nueva problemática. La región industrial del Ruhr debe mejorar la conexión y las condiciones de este vasto territorio, atravesado por sistemas viarios, carreteras e industrias. Una de las propuestas ganadoras conserva en gran medida las preexistencias y pone el valor el legado industrial como elemento de identidad. A continuación recogemos una infografía que resume los agentes implicados en la transformación del Emscher Park, la superficie de zonas verdes (457 $\left.\mathrm{km}^{2}\right)$, los proyectos llevados a cabo (425), la clasificación en 5 zonas y los principales ejes de acción ${ }^{67}$.
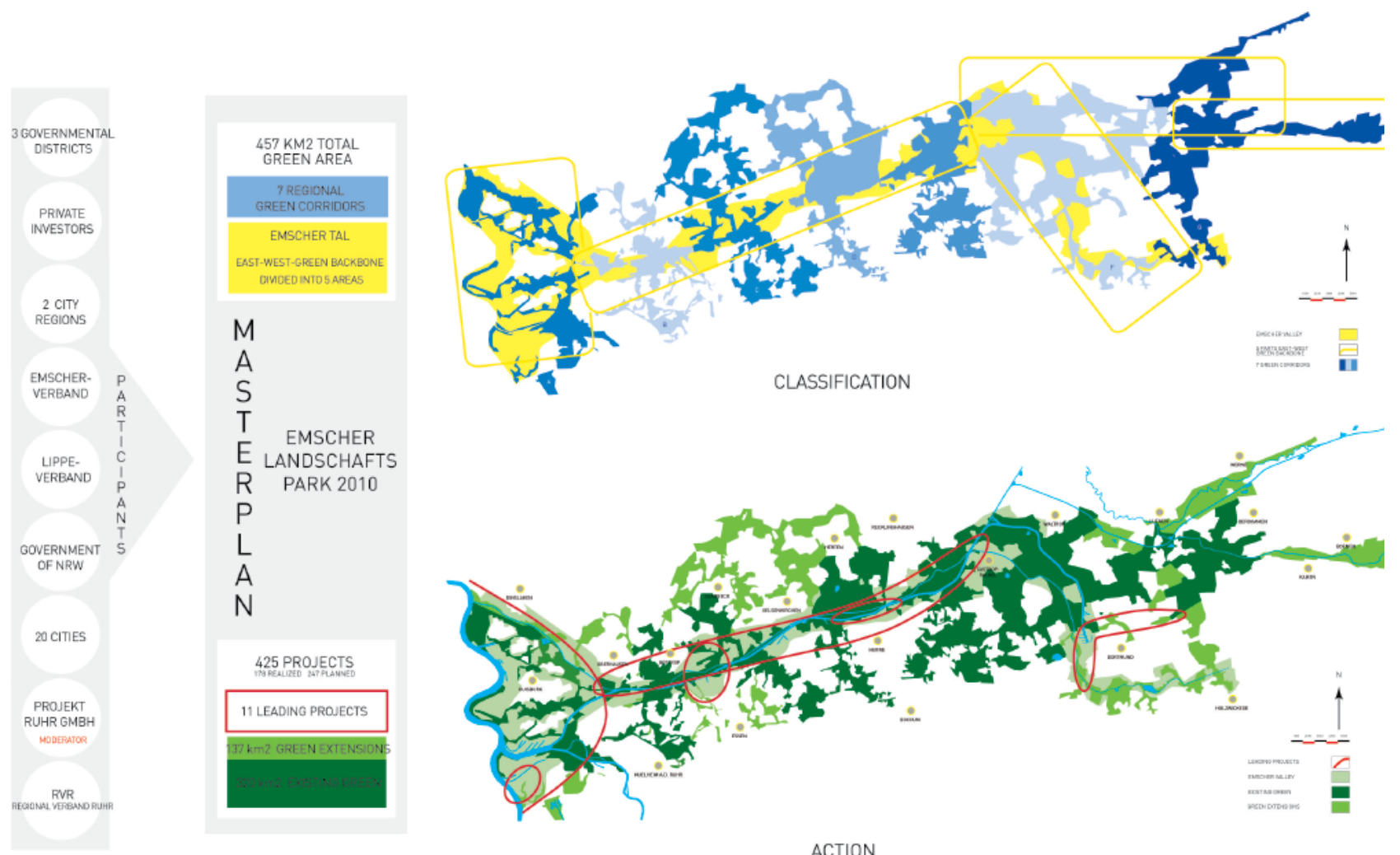

ACTION

Fig. 13 Master plan del Parque Emscher 2010. Fuente: Beyond Plan B.

La mayoría de fábricas cerraron en 1983. Tras años de inversiones externas, desde 1995 la zona del Rhein-Ruhr de 7.836 $\mathrm{km}^{2}$ es el área urbana más extensa de Europa y está reconocida como una de las grandes regiones metropolitanas europeas. Éstas se caracterizan por tener un impacto más allá de sus fronteras nacionales debido a funciones específicas que destacan a escala internacional. Sobre las regiones metropolitanas alemanas-europeas, "se espera que mantengan

67 http://beyondplanb.eu/projects/project_emscherpark.html 
la capacidad productiva y competitividad de Alemania y Europa como motores de desarrollo social, económico y cultural" ${ }^{68}$. El cambio viene auspiciado por una fuerte apuesta por la educación y la cultura. "Un buen ejemplo de esto es que hasta el siglo XX no había ninguna universidad o escuela técnica en el Ruhr" 69 . Hoy en día "con 22 Universidades, la región del Ruhr tiene la mayor densidad de centros de educación superior de Europa"70. Además, es cinco veces mayor que Berlín y cuenta con el doble de población. Todo ello prueba su capacidad de atracción de talento y población, vinculada a una fuerte identidad industrial.

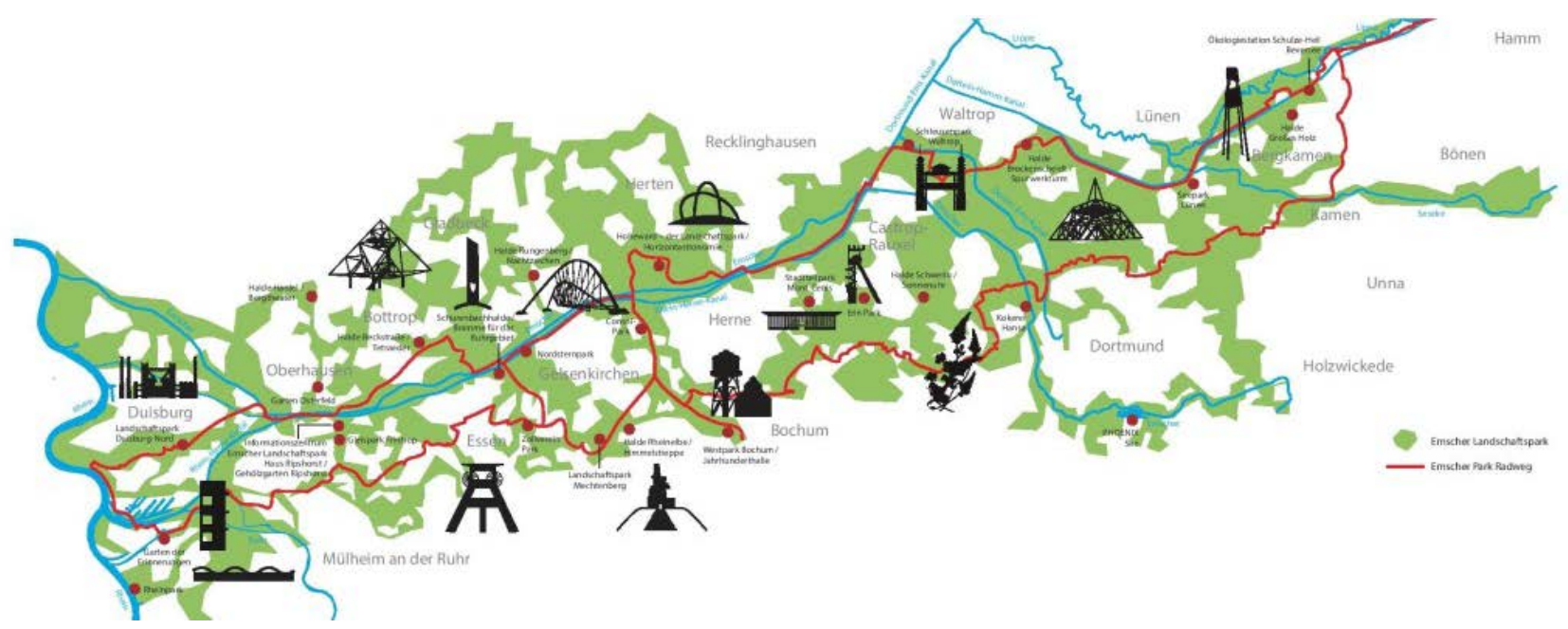

Fig. 13 Recorrido ciclista y puntos singulares del Parque Emscher. Fuente: http://emscherlandschaftspark-blog.de/emscherlandschaftspark_erleben/karte/.

"Las antiguas catedrales de la minería y los altos hornos, se han convertido en un reino del sector servicios" ${ }^{71}$. Las estrategias que se han seguido para coordinar esta región están vinculadas al impulso de sus paisajes culturales, cuyos elementos principales son: paradas emblemáticas, recorrido y relato conjunto. En este caso, se ha regenerado el paisaje con la creación de un imaginario colectivo basado en las preexistencias industriales. Se ha mejorado la conectividad entre centros urbanos mediante transporte público y con una gran red de carril bici. Por último, se ha generado una comunicación e imagen de marca conjunta entre los espacios culturales y las paradas-mirador; todo ello fomentado por eventos conjuntos como festivales o exposiciones itinerantes que promocionan el conjunto. Además se generan sinergias con otras regiones culturales-industriales, como muestra la exposición reciente en Cataluña: Industria, Territorio, Identidad. Como punto de reconocimiento internacional destaca la Capitalidad Cultural Europea en 2010, con una afluencia de público masiva como vemos en la imagen inferior derecha.

68 (2006) RVR, Regionalverband Ruhr, Regionalkundliches Informationssystem des RVR zum Ruhrgebiet, Glossar, www.ruhrgebiet-regionalkunde.de/homeregionalkunde/glossar/rahmenpl.html

69 Romero Renau, L. (2009) Planificación territorial en regiones industriales maduras: el caso del Ruhr (Alemania)

70 www.welcome.ruhr/en/career/studying/

71 Poch, R. (25-10-2010) La región del Ruhr ensaya modelos de creación como capital cultural; en la Vanguardia. 

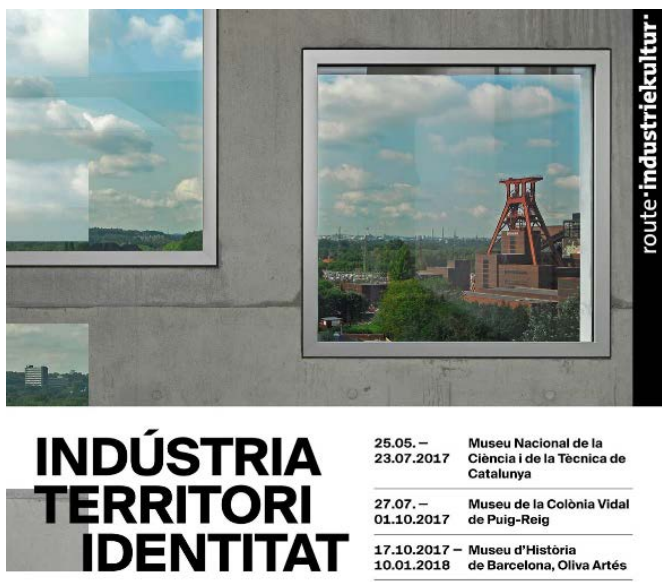

La Ruta del Patrimoni Industrial del Ruhr visita Catalunya

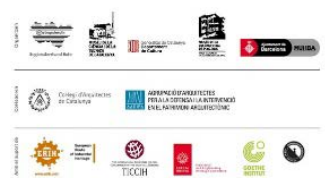

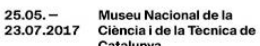

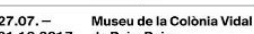
17.10.2017 - Museu d'Historia
10.01.2018 de Barcelona, Oliva Artés

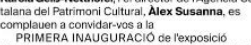

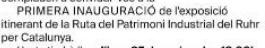

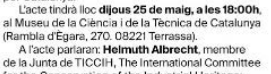

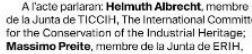

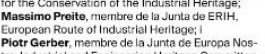

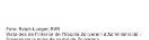

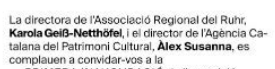

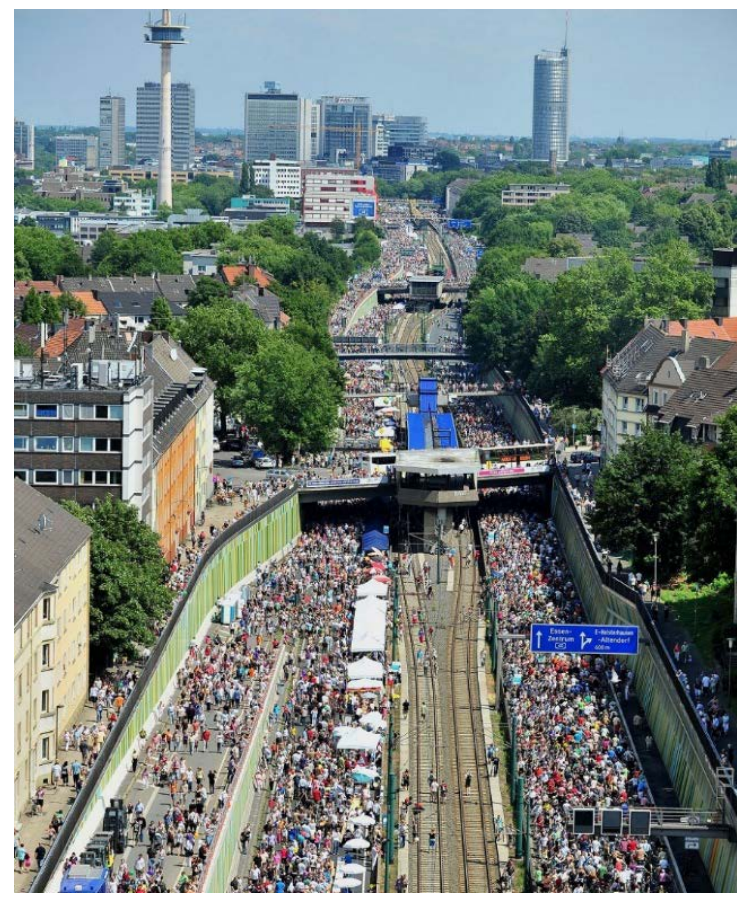

Fig. 13 Poster de presentación de la exposición: Industria, territorio, identidad. Fuente: Ayuntamiento de Barcelona, MUHBA, mNACTEC y Ruhr Metropole.

Fig. 14 Salida en Essen de la carretera A40/B1, que une Dortmund y Duisburg, ocupada por participantes de los eventos organizados por la región del Ruhr por motivo de su capitalidad cultural europea en 2010 (18 de Julio). Fuente: A Metropolis in the Making, Evaluation of the European Capital of Culture RUHR.2010, ZFKF Centre for Cultural Research.

En conclusión, tanto la provincia de Barcelona, como la región Metropole Ruhr han invertido en infraestructuras y planes culturales con un enfoque enraizado en la cultura local de base industrial, y al mismo tiempo con ambición global. Ambas están en la línea de los objetivos europeos de fomento del conocimiento, reconocido como la estrategia Lisboa (2000). El estudio regional del nuevo Ruhr (Keil y Wetterau, 2013) recuerda como: "la Unión Europea tiene la intención de convertirse en la primera región del mundo de economía basada en el conocimiento para 2010". Pero para ello ha sido necesaria la confluencia de muchos factores. Kunzmann (1995) reconoce el potencial de los planes regionales para cohesionar territorios al tiempo que critica la dificultad para comunicar y llevar a cabo ese potencial con los responsables políticos. Tanto el caso de la región de Barcelona como la del Ruhr son ejemplos de cómo la sociedad civil, política y académica han confluido para dibujar juntos nuevos paisajes sociales, culturales y económicos. La manifestación de ese esfuerzo va más allá de eventos o planes puntuales, permite desarrollar redes de colaboración que perduran y consolidan el territorio. Las redes culturales son una muestra más de regiones y ciudades cada vez más interconectadas y complejas. En este contexto, las fábricas culturales son un componente fundamental promoviendo el desarrollo cultural desde la tradición local. Estos espacios permiten reciclar la infraestructura industrial, devolviendo a la vida a sus paisajes sin olvidar su pasado. Además, suponen un empuje de largo recorrido frente al desarrollo de actividades y eventos puntuales. 


\section{REFLEXIÓN FINAL}

Las transformaciones culturales llevadas a cabo en la región del Ruhr y Barcelona nos ayudan a repensar las posibilidades de un territorio industrial deteriorado. Ambos casos han mejorado sus conexiones culturales basándose en las funciones tradicionales de cada lugar y maximizando el uso de las infraestructuras existentes. Si bien el éxito de estas operaciones puede estar vinculado a las grandes inversiones públicas, lo que dificulta su asimilación en otras latitudes o incluso en territorios similares en momentos históricos con menor auge económico, hay lecciones que se pueden extraer de ambos casos, ya que, la consecución de los objetivos de ambas reconversiones se ha confirmado y establecido con el paso de los años.

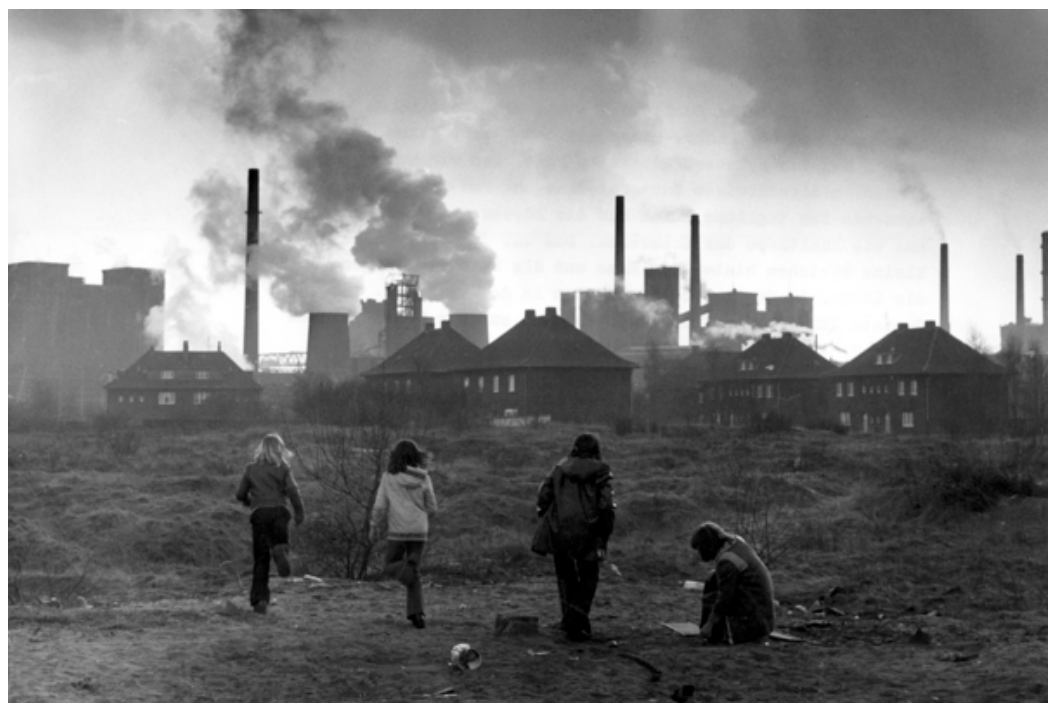

Fig. 15 Paisaje industrial del Ruhr previo a la transformación paisajística y cultural. Fuente: www.ftm.nl/uploads/2013/Ruhrgebied.jpg

En primer lugar, los planes urbanísticos deben ser extremadamente sensibles al entorno y creativos, capaces de adaptarse a los tiempos y plantear cuáles serán los motores del desarrollo futuro. Autores como Sabaté (2003) destacan que, en los próximos planes regionales, tanto el paisaje, como la cultura, tendrán un papel fundamental. En este contexto, poblaciones en declive podrían revitalizarse, como los antiguos asentamientos industriales. De hecho, ya está sucediendo en torno a proyectos de Paisajes Culturales como el del Valle del Llobregat. Todo ello nos invita a reflexionar sobre la oportunidad de reutilizar infraestructuras y zonas en desuso frente a propuestas que rompen con el pasado. Si bien los costes económicos parecen similares, deben tenerse en cuenta otros factores como: el beneficio social, cultural y ecológico.

Por otra parte, este artículo permite comprobar la larga tradición del planeamiento territorial de ambos casos de estudio, Ruhr y Barcelona, que dan lugar a su interconectividad actual, no como el fruto de un hecho aislado, sino como el resultado de un proceso prolongado de superposición de capas naturales, técnicas y culturales. Las redes de patrimonio industrial han sabido sobreponerse a los periodos de decadencia y están contribuyendo a coser territorios rurales, convirtiéndolos en regiones atractivas, diversas y desarrolladas. Diferentes eventos como las Olimpiadas y la Internationale Bauausstellung (IBA) fueron momentos de impulso cultural de la región que facilitaron su regeneración territorial y urbana. Aún queda mucho trabajo por hacer, en la actualidad, tanto la región de Barcelona, como la del Ruhr, continúan en la búsqueda de financiación central e internacional para mantener la calidad de sus servicios. Por el momento, las diferentes exposiciones menores, continúan difundiendo la labor de diversas asociaciones locales y mostrando como la transformación, de región puramente industrial a paisaje cultural de reconocimiento internacional, es costosa, pero posible. 


\section{BIBLIOGRAFIA}

ÁLVAREZ-PALAU, E. J. (2015). Xarxa ferroviària i sistema de ciutats. Tesis doctoral dirigida por Herce, M., Magrinyà, F. y Martí-Henneberg, J. ETSECCPB-UPC.

BIANCHINI, F. Y PARKINSON, M. (1993). Cultural Policy and Urban Regeneration: the West European Experience. Manchester University Press.

CABALLÉ, F. (5 Noviembre 2010). Desaparece el barrio de Icària, nace la Vila Olímpica. Biblio 3W. Revista Bibliográfica de Geografía y Ciencias Sociales, Universidad de Barcelona, Vol. XV, no 895 (9).

CARRERAS, J. M. BERNAT, J. Y RIERA, P. (2009) El Pla general d’obres públiques de 1935: política, infraestructures i territori

CASANELLES, E. (2007). El Sistema territorial del mNACTEC: bases i conceptes.

CASANELLES, E. (2013). Un museu per a un país: el Sistema Territorial del mNACTEC p.22 y 18 Cataluña: mNACTEC

CONNOLLY, M. G. (2011). The 'Liverpool model(s)': cultural planning, Liverpool and Capital of Culture 2008

DENNIS, R. (2008). Urban modernity, networks and places. England: Cambridge University Press

DOMINGO, M. (1986) Xarxa ferroviària i construcció urbana a Catalunya. Tesis doctoral dirigida por Manuel Ribas. ETSAB-UPC.

FONT, J. (1993) La formació històrica de la xarxa de carreteres a Catalunya (1761 -1935)

GARDINER, F. L. KOSMALA, K. (2017). The Role of Cultural Planning Methodology in Contemporary Cultural Studies: The Case of Post-Industrial Cities.

KAZEPOV, Y. Y SENNETT, R. (2008). Capitalism and the City: Globalization, Flexibility, and Indifference. En Cities of Europe: Changing Contexts, Local Arrangements, and the Challenge to Urban Cohesion. Oxford: Blackwell.

KEIL, A. Y WETTERAU, B. (2013) Metropolis Ruhr. A Regional Study of the New Ruhr

KNAPP, W., KUNZMANN, K. R. Y SCHMITT, P. (2003). RheinRuhr. En: Meijers, E. J., Romein, A. y Hoppenbrouwer, E.C. (eds.): Planning Polycentric Regions in North West Europe, EURBANET, Delft.

KUNZMANN, K. R. (1995): Developing the Regional Potential for Creative Response to Structural Change. En: Brotchie, J., et al. (eds.): Cities in Competition: Productive and Sustainable Cities for the 21st Century. Melbourne, Longman, p. $386-230$.

LABELLE, J. M. (2001). Emscher Park, Germany, expanding the definition of a "park"

MEINRAD (2016). European Industrial Heritage: The International Story. Contribución del ERIH para el año Europeo del Patrimonio.

MÉNDEZ, F. P. (1999). Experiencias Recientes. Debates abiertos en La ciudad deseada. Valorización cultural de la ciudad histórica, su evolución sostenible y su futuro en la previsible ordenación del territorio. Castilla y León: Fundación del Patrimonio Histórico. 
NAVAS T. (2008) Modernitzar el territori: la planificació i construcció de la xarxa de carreteres de l'àrea de Barcelona pág. 123 (Traducción propia)

NAVAS T. (2012) Crecimiento Urbano, red de carreteras y Tranvía Eléctrico en el Área de Barcelona.

PARDO, C. J. (2016). El Patrimonio industrial en España. Paisajes, lugares y elementos singulares. España: Akal.

POCH, R. (25-10-2010) La región del Ruhr ensaya modelos de creación como capital cultural; en la Vanguardia.

ROH, Y. H. (2007). The Rise of the Ruhr Area, Germany's Industrial Heartland, in the 19th Century.

ROMERO, K. (2017). [FÁBRICAS Y REDES] CULTURALES. Elementos patrimoniales estratégicos para organizar el territorio.

ROMERO, L. (2009) Planificación territorial en regiones industriales maduras: el caso del Ruhr (Alemania)

SABATÉ, J. (2003) El patrimonio como recurso básico para un nuevo modelo de desarrollo. Urban, 9.

SABATÉ, J. (Octubre 2008) Globalización y estrategias urbanísticas: Un balance del desarrollo reciente de Barcelona. Cuaderno Urbano, Volumen VII.

SCHMIDT, R. (1912) Denkschrift betreffend Grundsätze zur Aufstellung eines General-Siedelungsplanes für den Regierungsbezirk Düsseldorf (Rechtsrheinisch).

SCHMIDT, S. Y BUEHLER, R. (2017). The planning process in the US and Germany: A Comparative Analysis. 